\title{
Model Materials for Irradiated Fuels: Study of Local Mechanical Behavior Using Nanoindentation and Microstructural Analysis
}

\author{
Nathalie Payraudeau - Le Roux ${ }^{1}$, Sylvain Meille ${ }^{1}$, Cyril Langlois ${ }^{1}$, Isabelle Zacharie-Aubrun ${ }^{2}$, Thierry \\ Douillard ${ }^{1}$, Jean-Marie Gatt ${ }^{2}$ \\ 1. INSA-Lyon, MATEIS CNRS UMR5510, F-69621 Villeurbanne, France \\ 2 CEA, DEN, DEC Cadarache, 13108 St Paul Lez Durance, France
}

Understanding and predicting nuclear fuels behavior during their use in reactors or transient tests require knowledge of their mechanical properties such as elastic modulus, hardness and resistance to fracture. In this study, a method combining nanoindentation, SEM and EBSD analysis was developed on cubic zirconia (from Microcertec) and ceria (from Kurt Lesker), two model materials of irradiated $\mathrm{UO}_{2}$. This approach aimed at overcoming the difficulty of making test-pieces for compression or flexion tests in fragmented and cracked irradiated fuels.

The model materials were chosen for their crystalline structure, microstructure and mechanical properties close to $\mathrm{UO}_{2}$ ones. The yttria fully-stabilized cubic zirconia used in the study had a microstructure (grain size, porosity) similar to the $\mathrm{UO}_{2}$ one while fracture toughness of ceria was closer to the $\mathrm{UO}_{2}$ one. The lower value of ceria fracture toughness also allowed the observation of crack propagation at lower loads, inside one grain.

Nanoindentation tests were performed inside grains and on grain boundaries at loads high enough to induce cracks. The range of loads used in this study was from $10 \mathrm{mN}$ to $10 \mathrm{~N}$. SEM observations enabled determination of the threshold load to initiate cracks and of the types of cracks obtained. These results showed a similarity with the fracture behavior of irradiated $\mathrm{UO}_{2}$ (as illustrated in Figure1).

SEM images were coupled with EBSD analysis in order to determine the influence of grain orientation and preferential cleavage planes (as illustrated in Figure2).

Indentation tests were also performed at higher loads to study the influence of microstructural heterogeneities such as pores and grain boundaries and in order to link local mechanical properties of the material to more macroscopic results.

Finally, instrumented indentation was used to assess fracture energy, as classical models using crack lengths for fracture toughness calculation [1-2] were not applicable in a large range of loads in the tested materials. Fracture energy is an important input for numerical simulations of irradiated fuel behavior. The method developed here will then be implemented on nuclear fuels.

\section{References:}

[1] Anstis, G. R et al, (1981), Journal of the American Ceramic Society, 64:533-538.

[2] Dukino, R. D et al, (1992), Journal of the American Ceramic Society, 75: 3299-3304. 


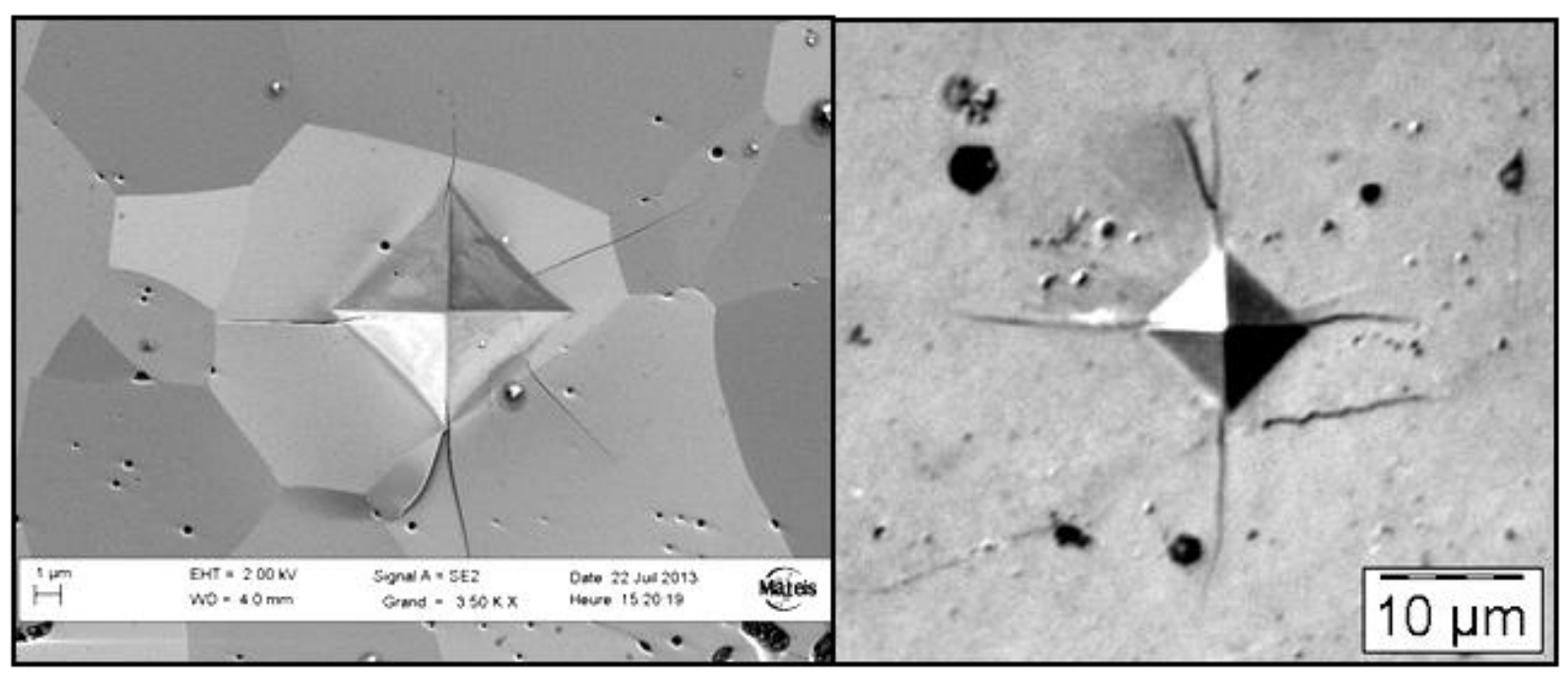

Figure 1. Vickers indentation at $661 \mathrm{mN}$ in cubic zirconia (left) and at $735 \mathrm{mN}$ in irradiated $\mathrm{UO}_{2}$ (right).

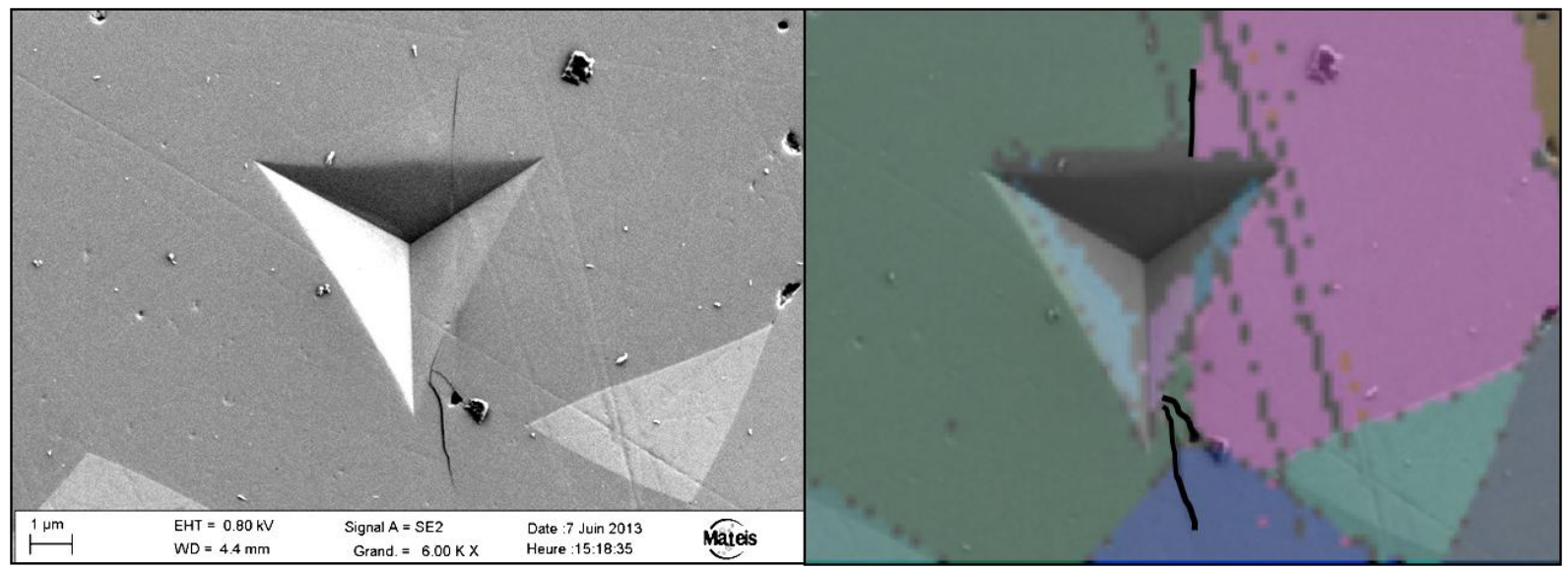

Figure 2. Berkovich indentation at $300 \mathrm{mN}$ in cubic zirconia (left). Superposition of SEM image and EBSD cartography (right). 